\title{
Hidden Tale of Pollution: Need of Solution
}

\author{
Swathi Gunduluru* \\ Department of Zoology, Government Degree and PG College, India
}

*Corresponding author: Swathi Gunduluru, Department of Zoology, Government Degree and PG College, Puttur, Andhra Pradesh, India

\section{Editorial}

Environment and human beings are too interlinked with each other as we are part and parcel of it. As human beings are shaping into super beings with help of science and technology in this process new pollutants are invited into environment on regular basis. We are just postponing and changing the dumping areas which eventually occupying environment making more complicated to clear. This means we are at high risk from those pollutants as they are occupying in all levels as we are unable to sustain far with all these dumping of pollutants. Environment is not advancing as fast as pollutants to degrade them through natural process and retain to normal condition. Products obtained from living organisms, have simple mechanisms to dispose and degrade them into useful forms. The dumping of nature as carbon deposits from millions of years stored in earth, are now released again into atmosphere by us. If we go on in this process, we will pay the price to our own acts. We know this from the eve of origin of life i.e., 3.5 billion years ago with many new combinations of chemicals and their fluctuations, kept many organisms at bay. Cyanobacteria released oxygen approximately 2.5 billion years ago, as oxygen, which increased slightly become a pollutant took its toll by killing many organisms. If we go through five mass extinctions occurred in past, we can clearly see pollutants are playing major role in creating disasters for living organisms. In Ordovician-Silurian mass extinction, carbon dioxide was sucked into rocks which caused glaciations causing many organisms death. In late Devonian mass extinction, Sulphur dioxide occurred as acid rains causing many organisms to perish. In Permian-Triassic mass extinction also called great dying may be caused by release of carbon dioxide, greenhouse gasses as methane which lead to global warming which indirectly lowered oxygen levels leading to mass extinction. In Triassic-Jurassic mass extinction, carbon dioxide levels were quadrupled making the mighty dinosaurs to death. In Cretaceous-Paleogene mass extinction, most of the species wiped out due to increase of components like Sulphur. From the above we can figure out if pollutants not treated, they will take their price wiping out organisms how mater big they are without showing mercy or forgiving. Now it's necessary to think and analyze how vulnerable we are to fight with pollutants. It is need of hour to find new solutions to clear pollutants with help of our co-organisms like plants and microorganisms to battle with pollutants. It is well known truth that microorganisms are used from dawn of humans, for our own benefits in food and spread it to medical applications, now we are extending them to degrade the pollutants. Microorganisms are living biotechnology laboratories which are boon for human race to modify and use them. These little soldiers can be genetically modified and use them for just to degradation of pollutants at all levels. They had lived through very harsh environment from their origin and have a great deal in using some of the pollutants as their substrates. Already there are so many microorganisms involved in bioremediation and biodegradation process, in these lines microorganisms should be used within control to protect us from the pollutants. We need to prepare not only for to clean up our pollutants but also be ready to clear any type of pollutants when occurred abruptly.

There should be many discussions and debates on the environment issues through which innovations and new findings will come out, without discussions and also without proper guidelines there will be more harassment to health of environment which ultimately takes it wrath on humans. We should now build up for living in this world with sustainable development and the scientists should focus on the environment pollutants to dispose them fast without much suffering of the environment. The advancements of Science and technology can't be sopped as that's what makes the humans to survive with less energy and happily comfortably but with this, we should also make new discoveries for the pollutant disposal. 


\section{(C) (1) This work is licensed under Creative}

To Submit Your Article Click Here: Submit Article

DOI: $10.32474 /$ CTBM.2019.01.000115

\begin{tabular}{c}
$\begin{array}{c}\text { Current Trends on Biotechnology \& } \\
\text { Microbiology }\end{array}$ \\
Assets of Publishing with us \\
- Global archiving of articles \\
- Immediate, unrestricted online access \\
- Rigorous Peer Review Process \\
\hline Current Trends on
\end{tabular}

